\title{
Collaborative and individual strategic planning effect on performance of an oral task
}

DOI: https://doi.org/10.21897/25394185.1484

\section{Impacto de la planificación estratégica colaborativa e individual en el rendimiento de una tarea oral}

Rafael Zaccaron, rafaelzaccaron@gmail.com.

Federal University of Santa Catarina, Florianópolis, Brasil.

\section{Resumen}

Este artículo reporta los hallazgos iniciales de un estudio de maestría en Lingüística Aplicada sobre el efecto que el planeamiento estratégico, colaborativo e individual tiene en el desempeño de una tarea oral en jóvenes estudiantes del inglés como L2 en Brasil. EL planeamiento estratégico (Ellis, 2003, 2005) es un concepto importante dentro del enfoque basado en tareas (TBA), ya que esta condición puede desencadenar procesos meta-cognitivos. Sin embargo, pocos estudios han tenido jóvenes estudiantes de inglés como participantes en la investigación de planeamiento estratégico. Los participantes, estudiantes adolescentes, inscritos en el segundo año de una escuela secundaria pública en Florianópolis (Brasil), realizaron dos tareas mono-lógicas orales bajo dos condiciones de planeación diferentes: (a) colaborativo, y (b) individual. Los mensajes orales enviados usando WhatsApp se analizaron en términos de precisión, fluidez y resultado (pragmático). Además, los participantes completaron cuestionarios después de la realización de cada tarea, con el objetivo de revelar su percepción sobre las condiciones y tareas. En este trabajo, se analizaron los datos del estudio piloto, además de algunos resultados preliminares. A pesar de la ausencia de resultados estadísticamente significativos para la exactitud y fluidez, los resultados indicaron una tendencia que respalda la condición de trabajo colaborativo. Si bien, los datos cualitativos mostraron un fuerte apoyo para la condición de planeamiento colaborativo. Estos hallazgos iniciales, en general, apoyan el uso de tareas orales L2 que involucran el planeamiento estratégico en el contexto de la escuela pública. Palabras claves: Trabajo colaborativo, planeación estratégica, pre-tareas, tarea oral en segunda lengua; WhatsApp, colegio público.

\section{Abstract}

This article reports the initial findings of an MA in Applied Linguistics on the effect collaborative and individual strategic planning have on performance of an oral task by young learners of English as an L2 in Brazil. Strategic planning (Ellis, 2003,2005 ) is an important concept within the task-based approach (TBA), as this condition may trigger metacognitive processes.Yet, only a few studies have had young learners of English as participants in strategic planning research. The participants, teenage learners,enrolled in the second year of a public high school in Florianópolis (Brazil), performed two monological oral tasks under two different planning conditions: (a) collaborative, and (b) individual. The oral messages sent using WhatsApp were analysed in terms of accuracy, fluency and outcome (pragmatic). In addition, the participants filled in post-task questionnaires after the performance of each task, aiming at unveiling their perception on the conditions and tasks. In this paper, data from the pilot study as well as some preliminary results were analysed. In spite of the absence of statistically significant results for accuracy and fluency, results indicated a trend supporting the collaborative work condition. While, the qualitative data showed strong support for the collaborative planning condition. These initial findings, in general, support the use of L2 oral tasks involving strategic planning in the public school context.

Keywords: Collaborative work, strategic planning; pre-task, L2 oral task; WhatsApp, public school. 


\section{Introduccion}

The use of L2 task-based language in the teaching and research contexts has enjoyed worldwide popularity in the last three decades according to Ahmadian and Garcia Mayo (2018). There has been a surge of empirical studies coming from China recently, while its applicability in Latin America remains low. In this context, the argument for using the TBA in classrooms is that it envisages the use of authentic language by learners performing meaningful tasks using the target language for teaching purposes. As far as evaluation goes, task-based performance has been widely accepted as indicative of language competence. It is presumed that «a learner's underlying competence can be inferred from their performance» (Haizhen \& Fangqi, 2015, p. 264) when performing a certain task. And some aspects have demonstrated to impact on performance such as: task familiarity (Bygate, 2001b), affective responses (Kormos \& Préfontaine, 2016), and task conditions (Foster \& Skehan, 1996). Strategic planning, being a task condition, has attracted attention from researchers interested in unveiling the different processes employed by learners under different planning conditions (D'Ely, 2006). From a cognitive perspective, planning is important in helping learners access their L2 knowledge through controlled processing, promoting selective attention to form and monitoring (D'Ely, 2006; Haizhen \& Fangqi, 2015). By virtue of working as a means to direct attention to different aspects of L2 production, strategic planning has been investigated by researchers under different formats. Collaborative strategic planning is one of the possibilities.

A number of studies involving collaborative work anchored on TBA principles (Beniss \& Bazzaz, 2014; Kowal \& Swain, 1994; Lynch \& MacLean, 2001; Storch, 2002; Xhafaj, Muck \&D'Ely, 2011, Xhafaj, 2013, to name a few) have demonstrated the impact of this condition on both performance and perception. Some of those (Xhafaj et al., 2011, Xhafaj, 2013) were interested in collaborative planning. However, these two studies focused on the pair work versus the individual planning conditions only. Drawing from Hyde (1993) and also the need to investigate different grouping setups (i.e., planning done by three or more students) due to large groups present in public schools, this study aims at investigating the effect individual and collaborative strategic planning have on performance of an oral task performed by Brazilian teenage learners of English as an L2.The analysis of collaborative planning work is based on Swain's (1985) output hypothesis.

This quasi-experimental study (Dornyei, 2007) adds to the body of Second Language Acquisition (henceforth SLA) research, more specifically to the field of research involving tasks due to the following points. First, there has been quite a few studies involving collaborative planning to perform a task. Although, to the best of my knowledge, no study has focused on the triad or four-people work arrangement specifically and its effect on planning and performance. Second, this piece of research involves technology in an embedded fashion, that is, the use of participants' own mobile phones to perform the tasks is integrated smoothly to the task cycle. Finally, considering that research in SLA has mainly focused on adult learners, the significance of this study relies on the fact that it was conducted at a public school in Brazil with teenage learners. This specific population has barely been the locus of SLA research.

\section{Theoretical background}

The use of strategic planning within a TBA framework has proved to be a prolific research area within SLA (D'Ely, 2006). Moreover, the notion of combining collaborative work with strategic planning for oral tasks seems appealing as it may ease the burden of performing cognitive demanding L2 tasks. In this context, the theoretical background of this work is presented. 


\section{Task-Based approach}

Considering the current vast amount of studies in the field (Guará-Tavares, 2016; Li, Chen \& Sun, 2015; Pang \&Skehan, 2014; Skehan, Xiaoyue, Qian, \& Wang, 2012; Specht, 2014, among others), one can affirm TBA still plays a central role in L2 research. While this central role tasks play in SLA is commonly accepted in the field, a clear-cut definition for tasks remains somewhat elusive. As the present piece of research is classroom oriented, a definition of task closely related to L2 learning is presented by Tavakoli and Foster (2011):

we take as a task anything that classroom language learners do when focusing their attention primarily on what they want to say to others or what others are trying to say to them. Language tasks closely resemble what learners do in their first language when they are, for example, telling stories, making plans, discussing problems, or explaining information, and as such, they are very common in communicative L2 teaching. (p. 39).

In addition to highlighting the classroom aspect, another relevant point in Tavakoli and Foster's definition is the link L2 tasks have to actions normally performed in the L1. The adaptability it offers in the classroom combined with the general positive acceptance by learners has turned the TBA a fruitful researcher area for experimental and action research studies in the SLA field.

Long (1991) and Skehan (2003) highlighted that, along learners' interaction, there should be a focus on form at some stage of the task so it fosters language acquisition. In other words, even in interactions where meaning is primary, there should be concern for form as well. Considering the idea of directing attention to form, the concept of attention is, therefore, linked to TBA research. According to Schmidt (2001), attention is a limited and selective mind resource and not a unitary phenomenon «...it refers to a variety of mechanisms. These include alertness, orientation, preconscious registration (detection without awareness), selection (detection with awareness within selective attention), facilitation, and inhibition» (p. 3). In this sense, attention can be understood as the ability to focus on a specific thought, in spite of competing attentional demands

With the aforementioned approach to attention, Skehan (2003) developed the concept of trade-offs in language performance. According to this notion, as learners attend to one aspect of performance complexity, accuracy or fluency - this may negatively impact the other dimensions as seen in Foster and Skehan (1996), D’Ely (2006) Guará-Tavares (2009) and Skehan et al. (2012). Aware of the role attention and trade-off effects play in task performance, research has focused on addressing ways to lessen the burden of online task processing, thus, strategic planning appeared as a response.

\section{$2 \quad$ Strategic planning for oral tasks}

Skehan (1996) has systematized in a framework the development of a task. According to this framework, the implementation of tasks consists of three distinctive phases: (1) pre-task, which has the goal to ease processing demands and improve performance, as attention might be shifted to language aspects as well as to the communicative goal; (2) mid-task, when decisions are taken online, during this stage, learners have their attention directed to solving the task, in other words, the focus should be placed on meaning; and, finally, the (3) post-task, when a moment of awareness raising occurs. Out of three stages, the pre-task offers the greatest possibility for manipulation by the task designer for it is planned in advance and it is not dependent on learners' response as the other phases (Foster \& Skehan, 1996). Among the different approaches to the pre-task stage, studies involving strategic planning (Ellis, 2003, 2005; D’Ely, 2006) have produced relevant results. 
While planning is intrinsically a cognitive process, strategic planning is a metacognitive action used by learners to facilitate the processing of language, which according to Levelt's (1989) model of L1 speech is complex and requires time and attention. D'Ely (2006) mentions that learners who are given the opportunity to plan strategically before performing a task can, at that moment, conceptualize, formulate and self-monitor their speech, which may facilitate linguistic processing. The results of empirical studies on strategic planning (D’Ely, 2006; Ellis, 2003; Ortega, 2005; Specht, 2014; Xhafaj et al., 2011, to name a few), point in general to the positive impact of this condition on different dimensions of performance. Strategic planning can present different setups such as collaborative planning.

\section{Collaborative work within TBA}

The output hypothesis (Swain, 1985, Swain \& Lapkin, 1998) states that L2 learners need to manipulate linguistic elements through collaborative dialogues (Swain, 2000) for L2 acquisition to occur. According to Swain, it is when learners have to produce (output) that they notice linguistic gaps in the target language, in other words, output may generate noticing. Once learners are aware of their L2 linguistics gaps, they will test hypotheses in order to communicate in a process between what they want to say and what they are able to say. Moreover, in this process of consciously reflecting upon language use, they might turn their attention to linguistic aspects in what Swain (2001) termed metatalk, when they verbalize and discuss micro aspects aspects of the message, such as syntax, that is, output may lead to metacognition awareness through metatalk. Swain points out that in producing output learners are pushed to move from semantic to syntactic processing, this movement is particularly appealing for L2 learning from a TBA perspectives as such language discussions happen in context. Considering both the attention that is necessary to notice linguistics gaps and the focus on form resultant of metatalk, the output hypothesis underpinning seems to be in consonance with strategic planning. And while the output hypothesis deals with production, one may argue that the interaction during collaborative strategic planning could be considered production due to its nature.

In relation to empirical studies that investigated collaborative work within the TBA framework, some convergence zones could be mapped. Collaborative work seems to help learners noticing gaps in their knowledge (Kowal \& Swain, 1994; Storch, 2002). In addition, performance may have a positive impact through collaborative work (Beniss \& Bazzaz, 2014). However, this difference in performance may not show statistical significance when learners plan in pairs (Xhafaj, 2013). Accordingly, some disadvantages have also been reported such as the anxiety of working in groups (Batstone, 2012), and a marked proficiency level imbalance (Lynch \& Maclean, 2001; Storch, 2002) that led learners to disregard their peers' contributions.

Yet, most of these studies had learners working in pairs. In respect to the interaction between learners, Hyde (1993) conducted a qualitative study whose participants demonstrated their preference for group work instead of individual or pair work, the latter being the least preferred condition. Therefore, the present study assumes that collaborative group planning, having 3 or more learners, may offer more positive results than the ones obtained in similar pair-work studies.

\section{Method}

Based on this brief literature review, strategic planning seems to foster better L2 task performance as it allows limited attentional resources to be directed to different aspects of production. Moreover, collaborative work indicates that learners could move beyond their individual capacities when planning together impacting on both production and perception. In order to expand previous findings 
encompassed within these issues, this quasi-experimental piece of research is guided by the following research questions, hypothesis and research design:

RQ1 - Is the oral performance of participants more fluent, accurate and appropriate when they plan in groups than when they plan individually? (within groups)

H1 - The oral performance of participants is more fluent, accurate and appropriate when they plan in groups than when they plan individually.

RQ2 - What are the participants' reported opinions on the two different planning conditions?

Table 1. Research Design

\begin{tabular}{cccccc}
\hline & $\begin{array}{c}\text { Group Division A and B } \\
\text { (first moment) }\end{array}$ & & \multicolumn{2}{c}{$\begin{array}{c}\text { Group Division A and B } \\
\text { (second moment) }\end{array}$} \\
\hline \multirow{3}{*}{ TCLE } & Group A & I.P (Task A) & & Group B & I.P (Task B) \\
& (8 learners) & I.P (Task B ) & Break & (9 learners) & I.P (Task A) \\
& Group B & C.P (Task A) & & Group A & C.P (Task B) \\
& (9 learners) & C.P (Task B) & & (8 learners) & C.P (Task A) \\
\hline
\end{tabular}

Note. I.P = Individual planning; C.P = collaborative planning; TCLE = ethics consent form; break $=20$-minute interval.

The information in table 1 shows the different phases of this study. This repeated measures design allows for a within-groups analysis, as all participants performed the tasks under the two different planning conditions, which is the independent variable. The meeting prior to data collection involved the invitation of participants and provision of the ethics agreement to be signed by both students and their parents. Then, in the second meeting - on data collection day - the group of seventeen students was split into two groups that were conducted to two separate rooms (group A and B). Within each group there was also a subdivision, so that participants were planning the two tasks (Task A and B) in both rooms (see table 1). This setup allowed that, for the second part of meeting 2, there was not only an inversion of planning condition (i.e., planning individually and in groups) but also of the tasks themselves. The rationale for using this design was to control for task effects. The tasks were applied on a single day with a twenty-minute break between the two moments, 12 minutes were allowed for planning for each task. The procedures involved with the implementation and execution of this movement are described next.

\section{$1 \quad$ Participants and Setting}

Seventeen teenage learners $(\mathrm{M}$ age $=16.11)$ enrolled in a public high school, maintained by a university, participated in the study in Florianópolis, Brazil. The majority of participants had received formal English instruction at school for 5-6 years. Although they were not tested for L2 proficiency, based on the interval they had studied English at school, it was expected they possessed an intermediate level of L2 proficiency.

\section{Oral tasks}

Two monological oral tasks (Tasks A and B) were adapted from previous studies(Mehnert, 1998; Xhafaj, 2013). Both tasks involved guided planning (i.e., containing instruction on relevant linguistic aspects the tasks required) and the use of participants' mobile phone ${ }^{1}$, as WhatsApp was the only 
requirement and all participants had this app on their phones.

Task A involved leaving an audio message to a friend on WhatsApp, creating an excuse to apologise for the participant's absence to a group meeting. In order to foster the production of more complex messages, the message had to contain the following mandatory words: house, to get andumbrella (no specific order). This task was adapted from the one first developed by Mehnert (1998), which was also used in Xhajaf et al.'s (2011) and Xhafaj's (2013) studies. Task B, like the task developed by Xhafaj et al. (2011), follows a similar structure of Task A. For Task B, learners had to leave an audio message to a teacher on WhatsApp, creating an excuse to apologise for the delay in delivering an assignment. The words: bus, to meet and computer needed to be part of the message (no specific order). The choice for these two tasks was based on the resemblance both of them have to real life situations, when people use their mobile phones to leave WhatsApp oral messages, and are, therefore, in line with the concept of tasks in TBA (Long, 2000; Tavakoli \& Foster, 2011). Moreover, the need to add those specific words could potentially trigger more interaction under the group work condition. Additionally, these tasks showed positive acceptance from the participants in the three previously mentioned studies (Mehnert, 1998; Xhafaj et al., 2011; Xhafaj, 2013).

\section{Collaborative group interaction}

Another source of data for this study was the audio conversation recorded while participants were planning collaboratively in groups. These interactions were recorded using three digital Sony IcdPx440 voice recorders. The objective of recording the interaction participants had while planning was to gather information as a means to corroborate the statistical analysis with qualitative data.

\section{$4 \quad$ Self-report questionnaire}

All participants also answered a self-report questionnaire. In order to minimise any possible misunderstanding the questions were formulated in Portuguese (participants' L1). The questionnaire was constructed to capture learners' different approaches to and how they perceived the two planning conditions. It contained questions such as: how did you like having time to plan? Did you find 12 minutes for planning enough time? Did you like to use your phone to record the task? Would you prefer planning with a peer/alone?, among others. This questionnaire was adapted from the one developed by Xhafaj (2013), containing a few amendments so it contemplated the use of WhatsApp.

\section{$5 \quad$ Procedures for Data Analyses}

In order to investigate participants' production and interaction, all recorded oral data were transcribed. The transcriptions were comprised of: WhatsApp voice messages and group interaction when planning collaboratively.

The WhatsApp audio messages were transcribed first and then assessed by three raters, one of which was an English native speaker. The following three aspects were measured by each rater: ASunits $^{2}$, accuracy and outcome.This first evaluation enabled the analyses of the oral messages under three different measures of speech production, namely, accuracy, fluency and outcome that were chosen for this study.

First, in regards to accuracy, errors were considered any deviation from the norm in regards to syntax, morphology, lexical choice or word order pointed out by the raters, each occurrence was counted as an error. The number of errors in each message was divided by the number of AS-units.

Second, for the evaluation of fluency the measure chosen was speech rate unpruned (SRU), which is a measure commonly used in studies assessing speech production (e.g., Foster \&Skehan, 
1996; D'Ely, 2006, Xhafaj, 2013). Speech rate unpruned is calculated by the total number of semantic units (complete words), including repetitions and self-repairs, divided by the total amount of time (in seconds) of participants' speech, this result is then multiplied by 60 .

Finally, considering the issue that a certain speech may be both accurate and fluent, yet it might fall short of achieving the communicative intended goal. And also, building up on Palotti (2009) and Michel (2017) who have recently called for the adoption of a different measure that would capture whether the speech had accomplished its communicative objective, the present study adapted the measure Farias (2014) developed in her study that was named outcome, which has a qualitative stance. In summary, the oral messages were analysed considering the number of errors (accuracy), how fluent they were (fluency) and how effectively they achieved the communicative goal of the task (outcome).

\section{Results from the pilot study}

Considering specific requirements this study possesses, such as testing new instruments and or procedures, a pilot study ${ }^{3}$ was planned and implemented to investigate whether: 1 ) the two tasks (A and B) were similar and adequate in terms of level of complexity for the participants of the study, 2) the planning time given to the participants sufficed the requirements to perform both tasks, and 3) any necessary adaptation was required. Six students from a different public high school were invited and accepted to participate of the pilot study. The reasoning for choosing the second school was that the English teacher worked with tasks, in being acquainted with the approach it was expected that participants would not feel overloaded by the cognitive demands of the tasks. The school English teacher selected the six students for the pilot based on oral performance in class. Time constraint restricted the possibility of the same participant planning both tasks (repeated measures) in the pilot. Nevertheless, having 3 participants planning individually and performing task A, while 3 participants planned collaboratively for task B in group sufficed the demands expected from the pilot study, that is, to test both tasks. Next, a brief summary of the findings from the pilot and the adaptation for the final data collection are presented ${ }^{4}$.

Table 2. Quantitative Data

\begin{tabular}{ccc}
\hline $\boldsymbol{P}$. & Fluency & Accuracy \\
\hline 1 & 70,9 & 0,75 \\
2 & 190,59 & 0,33 \\
4 & 73,3 & 0,5 \\
5 & 88,42 & 0,14 \\
\hline
\end{tabular}

Source: Zaccaron, D’Ely, Xhafaj (2018)

Table 2 presents the data for the two targeted oral measures in the pilot study. As one participant decided to stop the process and not record the message and a second learner's oral production did not yield enough utterances for analysis, table 1 shows the values for fluency and accuracy of the four oral messages. Participants 1 and 2 performed task A, while participants 4 and 5 performed task B. When the results are analysed as a group, the variable fluency - measured in speech rate unpruned - showed a gap in variance between 70,9 and 190,59, in a previous study (Xhafaj, 2013) the gap for fluency varied between 62,7 and 237. For accuracy the variance ranged from 0,14 to 0,75, while Xhafaj (2013) reported results for accuracy varying from 0 to 1,25 . This analysis indicated that the two tasks offered 
similar levels of complexity, as participants' oral production displayed levels of accuracy and fluency varying within an expected range, as seen in table 1.

The two tasks could, therefore, be considered as similar tasks for data analysis, constituting the pilot study's first finding. Second, the planning time of 7 minutes was tested. The results based on the notes taken by the researcher, interaction among participants, and self-report questionnaires showed evidence indicating that this slot of time was not enough for planning as participants displayed anxiety during planning and reported the lack of sufficient time as the main constraint for task performance, as P. 1 reported «There wasn't enough time, but I did rehearse a bit (laughing). There, afterwards, I had difficulties... $\|^{5}$ For the final collection, the planning time was increased to 12 minutes, which yielded more positive results from learners in the final collection. Third, each task had a set of three mandatory words as shown in section 3.2. Initially, one of the planned words was the verb 'to bring', however, during data collection for the pilot it was noticed that participants did not know the meaning of this verb. Considering that comprehension of the three mandatory words by participants was a requirement for task completion, this verb was, therefore, replaced by a more frequent verb in English, 'to get'6, for the final collection. Overall, the planning, implementation and data analysis from the pilot study allowed not only for important necessary adjustments to the organization of the final collection, a similar process pointed out in Bailer, Tomitch \& D'Ely (2011), but also the development of a novice researcher in charge of an empirical study.Next, some preliminary results from this study (final collection) are presented.

\section{Preliminary results from the main study}

The descriptive statistics of the three variables analysed (fluency, accuracy and outcome) indicated that data from this study were normally distributed for two variables (accuracy and outcome) with Kolmogorov-Smirnov sig = 0,2, for both individual and collaborative group condition. Fluency showed a sig $=0,46$ and 0,36 (individual and collaborative group respectively); however, the inspection of histograms for this variable confirmed that data were close to normal distribution, allowing the use of parametric tests. Next, a summary of the descriptive statistical data is shown in table 3 .

Table 3. Descriptive Statistics - individual planners and collaborative group planners

\begin{tabular}{cccccc}
\hline Variables & Condition & Min & Max & M & SD \\
\hline \multirow{2}{*}{ Fluency } & Individual & 43,30 & 198,60 & 109,87 & 41,09 \\
& Collaborative & 68,60 & 177,70 & 116,94 & 33,92 \\
\multirow{2}{*}{ Accuracy } & Individual & 16,67 & 276,92 & 143,13 & 82,40 \\
& Collaborative & 16,67 & 233,33 & 122,83 & 68,84 \\
\multirow{2}{*}{ Outcome } & Individual & 6,30 & 28,60 & 17,79 & 7,12 \\
& Collaborative & 6,70 & 29,70 & 19,37 & 6,96 \\
\hline
\end{tabular}

Note. Min = minimum score Max $=$ maximum score; $\mathrm{M}=$ mean; $\mathrm{SD}=$ standard deviation

The data in table 3 indicates values for both the fluency and outcome measures with higher figures for the collaborative planning condition: (1) fluency collaborative planning $\mathrm{M}=116$, 94, individual planning $\mathrm{M}=109,87$; (2) outcome collaborative planning $\mathrm{M}=19,37$, and individual planning $\mathrm{M}$ $=17,79$. Accuracy values also favoured the group planning condition, as higher figures indicated more errors. Accuracy for collaborative planning $\mathrm{M}=122,83$, and individual planning $\mathrm{M}=143,13$. 
Although not showing steep difference in means, it is already possible to note a trend in favour of collaborative planning for the three oral measures investigated. On average, the messages produced after collaborative planning were $6 \%$ faster in terms of speech rate, $14 \%$ more accurate, and scored $8 \%$ higher on outcome when compared with the messages produced after individual planning, indicating a possible focus on form (Long, 1991) during collaborative planning. Moreover, these results are similar to the ones found by Xhafaj et al. (2011).

In order to verify whether those differences found in favour of collaborative planning were statistically significant the parametric version of paired-samples t-test were run. The following results were yielded: (1) fluency $p=0,285$; (2) accuracy $p=0,148$, and (3) outcome $p=0,086$. Considering that to achieve statistical significance the value for alpha $(p)$ had to be equal or lower than 0.05 , out of the three measures only outcome approached significance with 0.086 .

In relation to the qualitative results, the pool of data was obtained through the answers to the self-report questionnaire.In order to measure participants' perception in relation to using their mobile phones and WhatsApp students answered the following Likert scale question: How did you enjoy recording the message using the mobile phone?

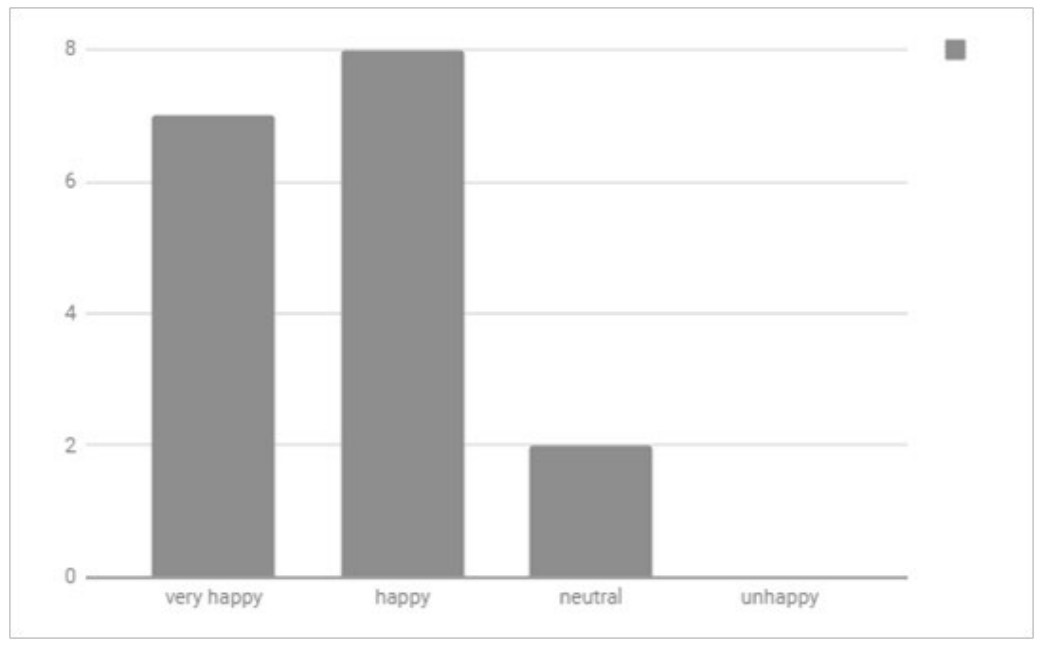

Graph 1. WhatsApp acceptance

Graph 1 indicates that $15(88,2 \%)$ students responded that they were either very happy or happy in using the gadget to complete the task, while $2(11,8 \%)$ participants answered they were neither happy nor unhappy. The unhappy option was not chosen by any participant. To justify her very happy choice P. 10 added «I thought I was talking to a real person, it felt real» 7 .

In respect to the two different planning conditions, namely individual and collaborative group, participants were asked which preference they had after completing the first task. 


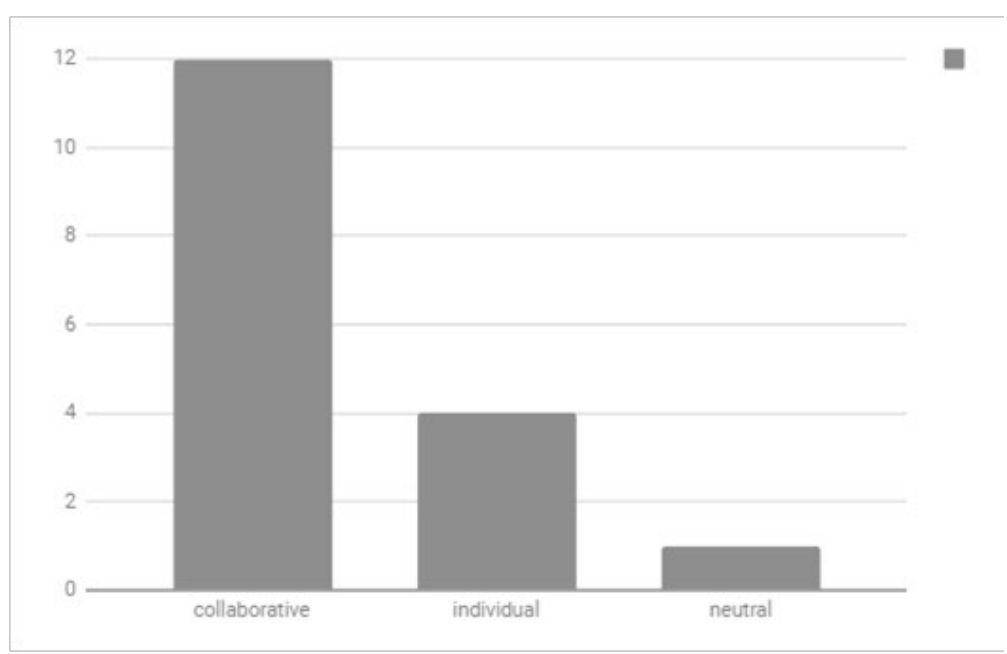

Graph 2. Students' Preferred Planing Condition.

Graph 2 shows that $12(70,6 \%)$ students reported their preference for the collaborative group planning condition; while $4(23,5 \%)$ participants preferred the individual planning; finally, $1(5,9 \%)$ learner showed no preference for either planning condition. The students who stated their preference for planning with peers highlighted, in general, that a partner could help or helped not only with unknown lexis but also with syntax, as they could improve their sentences. As a result, planning fostered by collaborative planning seems to have triggered attention to move from semantic to syntactic aspects as posited by Swain (1985) in her output hypothesis.

\section{Discussion}

The present research is part of an ongoing Masters in Applied Linguistics thesis, therefore, the discussions presented here are the first insights to emerge from the initial data analysis. In light of this, the aforementioned results from the pilot study and part of the data from the final collection have already provided an initial fruitful panorama for this discussion.

First, in relation to the pilot study. The planning and execution of the pilot study has been an important phase for this piece of research, as it was an opportunity for testing the instruments and procedures. Moreover, it was a relevant tool for allowing necessary amendments to be noticed and rectified for the final collection, thus the findings are in line with the posits pointed out by Bailer et al. (2011) concerning the benefits of carrying out a pilot. Finally, it also helped the researcher to have the first contact with the research locus, this was essential in helping him to feel at ease for the final data collection (Zaccaron et al. 2018). Considering the aforementioned positive aspects involved in the process of planning and implementing the pilot study, we highly recommend such movement for novice researchers in the SLA field who intend to conduct empirical studies.

In respect to the statistical analysis, although significant difference was generally not reached when comparing participants' performance for collaboratively planning, results are suggestive of the positive effect of the collaborative group condition. While the variables fluency and accuracy did not show statistically significant values, despite the means favouring the collaborative group condition, the variable outcome, which has a qualitative stance, approximated significance with $p=0,86$. These results are different than initially planned, as it was hypothesized that collaborative planning would impact showing statistically significant results on the three oral dimensions analysed. On the one 
hand, as learners seemed to focus on the outcome of the message primarily, results are in line with the literature on tasks concerning the importance of meaning first (Ellis, 2005; Long, 1991, Tavakoli \& Foster, 2011); on the other hand, it could be argued that this focus on meaning may have been the reason there were no statistically significant result for fluency and accuracy as these measures were penalized according to the trade-off effect (Skehan, 2003). Another relevant aspect from the pool of data is that the standard deviation values for all variables showed strong variance, which indicate a heterogeneous group concerning L2 proficiency. Thus, individual differences (Batstone, 2005; Ellis, 2005; Ortega, 2005) might have played a significant role in the quantitative results. However, the gap for standard deviation presented lower values for the three dependent variables under the collaborative condition, an indication that the opportunity to plan collaboratively resulted in more uniform performances, which is interesting for pedagogic purposes. Finally, in relation to research question 1 - Is the oral performance of participants more fluent, accurate and appropriate when they are planning in groups than when they are planning individually? -one cannot confirm that the tested condition had an effect on the results in statistical terms. Only the variable outcome seemed to partially show an statistically significant result, when participants planned collaboratively in opposition to when they planned individually.

In addition to providing a meaningful context for the use of the task, the adoption of participants' own mobile phone seemed to render a positive perception of this tool, with over $85 \%$ of participants signalling they were either happy or very happy when using their mobile phones for the tasks. Participants were particularly enthusiastic prior to data collection, as they already knew they would have to use their mobile phones. Some of them also reported that the task seemed like a 'real task' because it resembled what they usually do, that is, use their mobile phone to communicate via WhatsApp. This finding goes hand in hand with the vast majority of definitions for a task, as a means to link what learners do in their L1 (Tavakoli\& Foster, 2011).

In relation to the perception participants had on the two planning conditions, answers from the questionnaire indicated a preference for the collaborative group condition. More than $70 \%$ of participants stated their preference for this condition after task completion. To justify their choice, some participants mentioned that the colleague(s)' help would be extremely useful in completing the task, as they could help each other not only with the meaning of unknown words but also the improvement of sentences, for example. Considering these aspects, research question 2 is retaken what are the participants' reported opinions on the two different planning conditions? - to which the answer is: although both planning conditions were perceived as positive, the majority of participants in this study indicated their preference for the collaborative planning condition.

\section{Conclusion and pedagogical implication}

This study has sought to understand the effect individual and collaborative strategic planning has on L2 oral production for Brazilian teenage learners of Englishat the high school level. Although the results discussed in this paper are preliminary, there seems to be a positive trend favouring the collaborative group planning condition, with similar results found in Xhafaj et al. (2011). The results were not statically significant in general, however, this might be explained in part due to the small sample analysed and also the substantial variance in students' performances. The research has also sought to understand the perception L2 learners had on the two planning conditions that were investigated, the participants of this study, in general, showed a preference for collaborative work as an effective tool for task completion. In relation to future research paths, research on collaborative group work would be more vigorous and effective were it to be conducted via longitudinal study. Despite these 
limitations, the findings here presented might have valuable implications to pedagogy as they signal an overall positive acceptance by a young population, in general, not investigated in TBA studies. Strategic planning, being individual or collaborative, could and should be incorporated in the public school context as a means to allow for the gradual incorporation of tasks to the L2 syllabus.

\section{Notes}

${ }^{1}$ All participants had the option to use spare mobile phones provided by the researcher. Only two decided to use the spare ones, with the vast majority preferring to use their own mobile phones.

${ }^{2}$ Foster, Tonkyn and Wigglesworth (2000) define AS-unit as "a single speaker's utterance consisting of an independent clause, or sub-clausal unit, together with any subordinate clause(s) associated with either" (p. 365). The rationale for this segmentation is syntactic. Moreover, the AS-unit considers repetition, false-repetition and pauses that are common features of SL learners' speech.

${ }^{3}$ According to Mackey and Gass (2005) the pilot study is "a small-scale trial of the proposed procedures, materials, and methods, and sometimes also includes coding sheets and analytic choices" (p. 43).

${ }^{4} \mathrm{~A}$ full account of the benefits in conducting a pilot study for both the research and the researcher, as it provides an opportunities for testing instruments and procedures, is analysed in Zaccaron, D'Ely, Xhafaj (2018).

5 "Não deu muito tempo, mas eu ensaiei um pouquinho (risos). Ali depois eu tive dificuldade..."

${ }^{6}$ According to the Corpus of Contemporary American English, the verb 'to bring' has a frequency of 38895 in this corpus, while 'to get' features 261116.

${ }^{7}$ Achei que parecia que estava falando com uma pessoa real, parecia real.

\section{References}

Ahmadian, M.J., García Mayo, M. P. (2018) Introduction. In: Ahmadian, M.J., García Mayo, M. P (eds.) 2018. Recent Perspectives on Task-based Language Learning and Teaching. Berlin, Boston: De Gruyter Mouton. Retrieved 13 Aug. 2018, fromhttps://www.degruyter.com/view/ product $/ 462793$.

Bailer, C., Tomitch, L., D’Ely, R.C.S. (2011) Planejamento como um processo dinâmico: a importância do estudo piloto para uma pesquisa experimental em linguística aplicada. Intercâmbio. Revista do Programa de Estudos Pós-Graduados em Linguística Aplicada e Estudos da Linguagem. v. 24, 129-146. ISSN 2237-759x.

Batstone, R. Language form, task-based language teaching, and the classroom context. ELT Journal. 66 (4), 459-467. doi: 10.1093/elt/ccs058

Beniss, A. and Bazzaz, V. (2014). The impact of pushed output on accuracy and fluency of Iranian EFL learners' speaking. Iranian Journal of Language Teaching Research. v.2(2), 51-72.

Bygate, M. (2001b). Effects of task repetition on the structure and control of oral language. In: Bygate, M., Skehan, P.,Swain, M. (org.). Researching pedagogic tasks: Second language learning, teaching, and testing, London: Longman.

D'Ely, R.C.S.F. (2006). A focus on learners' metacognitive processes: the impact of strategic planning, repetition, strategic planning plus repetition, and strategic planning for repetition on L2 oral performance (Unpublished doctoral dissertation). Universidade Federal de Santa Catarina, Florianópolis, Brazil.

Dornyei, Z. (2007). Research Methods in Applied Linguistics: Quantitative, qualitative and mixed methodologies. UK: Oxford University Press. 
Ellis, R. (2003). Task-based language learning and teaching. Oxford: Oxford University Press.

Ellis, R. (2005). Instructed Second Language Acquisition: a Literature Review. Auckland UniServices Limited. Auckland: New Zealand.

Farias, P. (2014). Task-Test: what lies beyond implementing a task-based assessment? Comparing learners' performance and unveiling learners' perception in a testing situation (Unpublished undergraduate dissertation). Universidade Federal de Santa Catarina, Florianópolis, Brazil.

Foster, P. \&Skehan, P. (1996). The Influence of Planning and Task Type on Second Language Performance. Studies in Second Language Acquisition, 18, 299-323. doi: 10.1017/ S0272263100015047

Foster, P. Tonkyn, A. \& Wigglesworth, G. (2000). Measuring Spoken Language: A Unit for All Reasons. Applied Linguistics, v. 21, 354-75. doi: 10.1093/applin/21.3.354

Guará-Tavares, M. G. (2009). The relationship among pre-task planning, working memory capacity and L2 speech performance: a pilot study. Linguagem\& Ensino (UCPel), v. 12, 165-194.

Guará-Tavares, M. da G. (2016). Learners' processes during pre-task planning and Working Memory Capacity. Ilha do Desterro, v.69 (1), 79-94. doi: 10.5007/2175-8026.2016v69n1p79.

Haizhen, W. Fangqi, S. (2015). Effects of strategic planning time on L2 paired oral test performance. Chinese Journal of Applied Linguistics (Quarterly). v. 38 (3), 263-276.

Hyde, M. (1993) Pair work - A Blessing or a Curse?: An Analysis of pair work from pedagogical, cultural, social and psychological perspectives. System, 21 (3), 343-348.

Kormos, J. Préfontaine, Y. (2016) Affective factors influencing fluent performance: French learners appraisals of second language speech tasks. Language Teaching Research, v. 21 (6), 699-716. doi:10.1177/1362168816683562

Kowal, M. Swain, M. (1994) Using collaborative language production tasks to promote students' language awareness. Language Awareness. v.3 (2), 73-93.

Levelt, W. J. M. (1989). Speaking: From intention to articulation. Cambridge, MA: The MIT Press.

Li, L., Chen, J. \& Sun, L. (2015). The effects of different lengths of pre task planning time on L2 learners' oral test performance. TESOL Quarterly, v. 49 (1) 38-66.

Lynch T. and Maclean J. (2001). "A case of exercising": effects of immediate task repetition on learners' performance'. In M. Bygate, P. Skehan and M. Swain (eds.) Researching Pedagogic Tasks: Second Language Learning, Teaching and Testing. Addison Wesley Longman. 141-162.

Long, M. (1991). Focus on form: A design feature in language teaching methodology. In: de Bot, K. Ginsberg, R.Kramsch, C. (Eds.). Foreign language research in crosscultural perspective. 3952. Amsterdam: John Benjamin.

Long, M.H. (2000). Focus on form in task-based language teaching. In R.L. Lambert and E. Shohamy (Eds.), Language policy and pedagogy (179-192). Amsterdam: Benjamins.

Mackey, A. \&Gass, S. (2005). Common data collection measures. In: Mackey, A. \&Gass, S. Second Language Research: methodology and design. Mahwah: Lawrence Erlbaum. 43-99.

Mehnert, U. (1998). The effects of different lengths of time for planning on second language performance. Studies on second Language Acquisition, 20, 83-108.

Michel, M. (2017) Complexity, Accuracy and Fluency in L2 Production. In: Loewen, S., Sato, M. The Routledge Handbook of Instructed Second Language Acquisition. New York: Routledge, 50-68.

Ortega, L. (1999). Planning and focus on form in L2 oral performance. Studies in Second Language Acquisition.

Ortega, L. (2005). What do learners plan? Learner-driven attention to form during pretask planning. 
In: Ellis, R (Eds.), Planning and task performance in a second language (77-110). Amsterdam and Philadelphia: John Benjamins.

Pallotti, G. (2009). CAF: Defining, refining and differentiating constructs. Applied Linguistics, v. 30 (4), 590-601. doi: 10.1093/applin/amp045

Pang, F. Skehan, P. (2014). Self-reported planning behavior and second language performance in narrative retelling. In: Skehan, P. (Eds.). Processing Perspectives on Task Performance, 95128. Amsterdam: John Benjamins

Schmidt, R. (2001). Attention. In: Robinson, P. (Eds.). Cognition and second language instruction. (3-32). Cambridge: Cambridge University Press.

Skehan, P. (1996). A Framework for the Implementation of Task-based Instruction. Applied Linguistics. 17 (1), 38-62. doi: 10.1093/applin/17.1.38.

Skehan, P. (2003). Task-based Instruction. Cambridge: Cambridge University Press.

Skehan, P. Xiaoyue, B. Qian, L. Wang, Z. (2012). The task is not enough: Processing approaches to task-based performance. Language Teaching Research. v. 16, 170-187.

Specht, A. (2014). The impact of strategic planning instruction on learner's accurate oral performance of English as a foreign language. (Unpublished Masters dissertation). Universidade Federal de Santa Catarina, Florianópolis, Brazil.

Storch, N. (2002). Relationships formed in dyadic interaction and opportunity for learning. International Journal of Educational Research. v. 37, 305-322.

Swain, M. (1985). Communicative Competence: Some roles of Comprehensible Input and Comprehensible Output in its Development. In S. Gass\& C. Madden (Eds.), Input in second language acquisition (235-253), Rowley, MA: Newbury House.

Swain, M. (2000). The output hypothesis and beyond: Mediating acquisition through collaborative dialogue. In JP Lantolf (ed.) Sociocultural Theory and Second Language Learning. (97-114). Oxford: Oxford University Press.

Swain, M. (2001). Integrating language and content teaching through collaborative tasks. The Canadian Modern Language Review, 58 (1), 44-63.

Swain, M. Lapkin, S. (1998). Interaction and second language learning: Two adolescent French immersion students working together. The Modern Language Journal, 82, 320-337.

Tavakoli, P., Foster, P. (2011), Task Design and Second Language Performance: The Effect of Narrative Type on Learner Output. Language Learning, 61, 37-72. doi:10.1111/j.1467-9922.2011.00642.x

Xhafaj, D. C. P.,Muck, K.E., D’Ely, R.C.S.F. (2011). The impact of individual and peer planning on the oral performance of advanced learners of English as a foreign language. Linguagem\& Ensino, v. 14, 39-65.

Xhafaj, D. C. P. (2013). One is good, two is better: Investigating the impact of peer-planning in the oral performance of intermediate L2 English learners. (Unpublished undergraduate dissertation). Universidade Federal de Santa Catarina, Florianópolis, Brazil.

Zaccaron, R., D’Ely, R.C.S.F., Xhafaj, D.C.P. (2018). Estudo piloto: um processo importante de adaptação e refinamento para uma pesquisa quase experimental em aquisição de 12. Revista do GELNE, v. 20 (1). doi:10.21680/1517-7874.2018v20n1ID13201 